\title{
On Pragmatic Identity Construction of Prosecutors in Criminal Courtroom Discourse*
}

\author{
Xia Chen \\ Zhejiang Yuexiu University of Foreign Languages \\ Shaoxing, China 312000
}

\begin{abstract}
According to the theories of pragmatic identity construction, pragmatic identity as a specific social identity is the actual embodiment, application and even an invented concept in the verbal communicative context. In light of the spirit of "Trial Centralism" in the new criminal procedure law, the study involves analysis of the pragmatic identity construction by focusing on the trial discourse of prosecutors. It is discovered in the research that prosecutors have typical discourse expressions in their own legal institutional identity construction.But in the dynamic context of trials, they could also possibly abuse their legal powers, arrogate to themselves the rights of other identities and even become law popularization staff to some degree, which, in turn, should be corrected properly in practical trial practice. Only by sticking to their priority role as legal supervisor and to their identity construction as prosecutors can judicial fairness and justice be soundly assured.
\end{abstract}

\section{Keywords—prosecutors; trial discourse; pragmatic identity}

\section{INTRODUCTION: PRAGMATIC IDENTITY AND ITS CONSTRUCTION}

As a new tendency of discourse or post-modern research occurs in the study of identity construction, more scholars of sociology, social psychology, psychology, communication, linguistics and other subjects begin to research the dynamic construction, consultation, management and transmission of identity in discourse based on social construction. Pragmatic identity is a pragmatic resource for speakers, and speakers can construct the identity at a certain time by invoking relevant language resources to adapt to the contextual factors,so as to increase the opportunity to realize communicative purpose. ${ }^{[1]}$ This research tendency on the view of identity is also one of the hot issues in the pragmatics ${ }^{[2,3,4]}$. The main features include: (1) an identity is a dynamic process; (2) an identity occurs in a concrete and specific interactive occasion; (3) communication can produce multiple identities,not an individual or changelessly sole identity; (4) identities are formed along with the whole process and contextualization of communication;(5) identities requires being constructed via discourse;(6) identities are participants' resources, emphasizing whether

*This article is the phased results of "Identity Construction from the Viewpoint of Attitude System --- the Discourse Research on the Litigation Subjects in Chinese Criminal Trials", the sub-project of the project "On Interpersonal Discourse" (Item number: GZYY003) from the Language Service and Cross-culture Research Center of Zhejiang International Strategy Research Institute(2016). identities are used, when and how they are used. ${ }^{[5]}$

It is the communication character of an identity, not its social or psychological one that should be investigated to study identity construction from the perspective of pragmatics. Therefore, it is not enough to highlight the types of identities, the mode and formation of discourse constructed or the relationship between discourse and identity. More attention should be paid to why speakers choose and construct the specific identity, how speakers realize the communicative purposes with identity selection and construction, what specific meaning and communicative effect speakers prefer to convey and achieve, what influence speakers intend to exert in the interpersonal relationship, and what kind of interpersonal strategies are applied in the dynamic course of identity selection and construction ${ }^{[4]}$.

As has been discussed, Identity research is usually conducted through its interactive impact and mutual construction with discourse from the perspective of pragmatics. To further explore the identity research, the following five corresponding questions should be included :

1. How does the construction of specific identities influence the meaning and understanding of language in context?

2. How does the construction of specific identities meet the communication needs?

3. How does the construction of specific identities impact on the expression and understanding of interpersonal meanings?

4. How does the construction of specific identities dominate the selection of specific language form?

5. How does the construction of specific identities affect the appropriateness and suitability of specific language ${ }^{[4]}$

Chen(2014) proposed five main paths for these five key questions, which have important guiding significance for carrying out identity research from the viewpoint of pragmatics.

Path I: Regard the identities chosen and constructed by speakers as an interpretive resource to interpret the meaning of discourse from the angle of identity.

Path II: Regard the identities chosen and constructed by speakers as an illocutionary resource or a transactional 
resource to explore how speakers realize certain communicative targets with specific identities constructed.

Path III: Regard the identities chosen and constructed by speakers as an interpersonal resource embodying selfidentity tropism, so as to further examine how speakers select and construct specific identities to be close to or alienate themselves from the communicative object.

Path IV: Regard the pragmatic identities chosen and constructed by speakers as an explanatory resource to explain the underlying reasons of the specific discourse features.

Path V: Regard the pragmatic identities chosen and constructed by speakers as an evaluative resource to find out whether the discourse in specific communicative situation has applicability, appropriateness and justification,etc. ${ }^{[4]}$

In this article, path II and path V will be combined together to analyze the pragmatic identities of prosecutors in trial discourse.

\section{CORPUS AND RESEARCH QUESTIONS}

The corpus used is composed of transcriptions of four criminal trials from the live trial broadcast of Zhejiang Courtroom online. A qualitative research method is used in this research. And the following two questions are probed into in this article:

1. How do the prosecutors construct their own specific pragmatic identities in criminal trials?

2. What new identities of the prosecutors might occur in their interaction with defendants and defense lawyers in the process of the whole criminal trials?

\section{RESEARCH BACKGROUND}

Since the second half of the 20th century, many linguists, sociologists (Bourdieu,etc.) and philosophers (Foucault,etc.) have argued that the meaning system in any domain is constructed by discourse resources. Discourse produces specific meanings and constructs social consensus by means of selecting linguistic and other semiotic materials, which is obviously embodied in the legal domain. Most domestic and overseas relevant researches state that the language practice (for example, the police interview, the courtroom discourse) in both law enforcement and judicial context is an important part in the whole legal practice ${ }^{[6]}$. Thereby, it is necessary to emphasize the function of discourse in its construction of legal authoritative identity in the contexts of legislation, law enforcement and judicature while probing into the legal authority of social meaning system. Bogoch(1999) points out that the courtroom discourse provides a very interesting research context for analyzing languages and identities, and identities are not only constructed through individual behaviors, but also the behaviors and evaluations of others ${ }^{[7]}$. Courtroom discourse has become a crucial source of corpora for researching identity construction because of the particularity of its participants and the procedural characters of institutional discourse. However, this advantage could also be the bottleneck to further the research on identity construction. Because the procedural regulations and conventionality of court discourse (including dialogues and allegations) are enforced strictly, and most identities of participants are determined beforehand, there are congenital deficiencies to completely overcome the deficiencies of dynamic research on identity construction ${ }^{[1]}$. Therefore, it is necessary to seek for feasible research paths, and interpret discourse in detail with practical corpus to find out the features of dynamic nature and negotiability in identity construction.

One of the essential contents in judicial reforms includes promoting the reform of litigation system centering around trial and ensuring that the factual evidences of every case for investigation, examination and prosecution could stand up the inspection of law. The specific requirements for Chinese trial system have been proposed in the new criminal procedure law promulgated in 2012, in which, the significance of Trial Centralism was particularly highlighted. Trial Centralism means that the whole criminal procedure system and activity are constructed and carried out centering around the trial procedure and the case investigation at the trial stage is substantive... The trilateral relationship among accusation, defense and judgment in a trial is the central structure of litigation ${ }^{[8]}$. From the nature of criminal procedure, the accusation system and the defense system are the two important elements of criminal procedure in our country, which are exercised by prosecutors and defense lawyers respectively. Prosecutors are regulated by law to perform two basic obligations when exercising their own rights: one is to punish crimes and the other to protect human rights. However, in reality, prosecutors are inclined to stress more punishment than legal protection. Between the prosecution and supervision duties they perform, they often prefer to apply the former one, which consequently causes the later one to be neglected easily.

As the representatives of public power, prosecutors enjoy high status in trial, which is only secondary to judges. The investigation on the language practice, roles and identities of prosecutors plays significant importance for understanding the mutual relation in the interactive discourse in trials and even the whole trial system. Although many scholars have conducted acute analysis on the relationship between prosecution and defense from the perspective of jurisprudence, there are few researches on the identity construction of litigation participants in the judicial practice concerning the discourse analysis from the perspective of sociolinguistics.

In view of this reason, the courtroom discourse of prosecutors are chosen to be the research object in this article based on the theories of pragmatic identity while integrating conversation analysis and the latest research results in pragmatics. Qualitative method with the trial corpus transcribed from online open videos of live trial broadcast are applied. The focus is to discuss the process and discourse strategy of identity construction of prosecutors in criminal trials.

\section{Pragmatic IDENTITY IN COURTROOM Discourse}

Based on the theories of pragmatic identity in this article, prosecutors may construct the same pragmatic identity with 
different discourse modes. Meanwhile, if prosecutors choose different pragmatic identities, it is possible for them to use different discourse modes. Moreover, to construct a pragmatic identity often involves the choices at multiple levels. Hence we need to consider those factors to determine the pragmatic identity chosen by prosecutors in specific discourse context. For prosecutors, they are not limited to construct legal identity in courtroom discourse, but also possibly a new identity constructed dynamically to meet the needs of a certain discourse purpose. Some new identities deviated from the legal duties might occur due to the abuse of "authoritarian discourse",undermining the legal authority.

\section{A. The pragmatic identity in the Discourse of performing Prosecution Duty}

As for the relationship between power and identity, it is safe to say that social identity exists in power relationships which is also obtained through power relationships. The process of exercising power creates multiple, overlapping or conflicting discourses, and it can further construct the multiple identity of an individual or a social group through personal narration. In trials, prosecutors not only represent public power to execute their offices of public servants, but also establish an equal and adversarial identity with the defendants and their agents in the court relationship. For further strengthening the court participants' recognition of prosecutors' status, they often emphasize their own identities via various discourse strategies and strive to construct, maintain or protect their own identities and status. The following dialogue could be taken as an endeavor by the prosecutor to construct his identity through discourse strategy with the power stipulated by criminal laws.

(1) Prosecutor 1: Why did the stallholder stop your car at that time?

Defendant: I accidentally knocked down his stall when I was reversing my car.

Prosecutor 1: Was there any loss to the stallholder?

Defendant: I thought there was no loss, because my car touched it lightly, but did not damage it. I was going to pay him RMB 100, but they didn't want the money. They required me to get out of my car with a bad attitude...

Prosecutor 1: Why did you stop the car? Was there someone in front?

Defendant: I turned around at the front intersection in order to find a bar, and then they stopped my car when they saw me. I stopped and they surrounded me. They began to blow my car windows heavily with a bad attitude...

Prosecutor 1: The question, I, as a prosecutor, asked you was: why did you stop the car? Was there someone in front?

Defendant: Because his wife stood in front of my car and blocked me.

In criminal trials, judges are only responsible for procedural investigations, and lawyers have relatively limited opportunities to ask questions.Substantive investigations are undertaken mainly by prosecutors. Therefore, it is most typical in topic control while prosecutors question defendants. With the aims to find out the truth of cases, represent the processes of crimes to courts clearly, and assure the defendants to accept the accusation finally, prosecutors often control topics to guide the direction of information flow which would help to support effectively for accusation of crime. It is clearly observed from the above dialogue that the public prosecutor has absolute control power in any stage in the whole period of the trial, who might have known the cause and effect of the whole case in advance. However, with the purpose to replicate the process of the crime to the court, prosecutors would deliberately lead the defendant to represent the whole process in detail. When the defendants' answers deviating from the focus of the question, the prosecutor immediately asked him to return to the topic with mandatory language and claimed his identity with words like "the question, I, as a prosecutor asked you was..." to show his identify, so as to tell the interpersonal meaning of his identity to the defendant correctly and demand the defendant to obey the prosecutor's rules in Q \& A arrangement.

\section{$B$. The pragmatic identity in the Discourse of performing legal supervisors' Duty}

Identity construction, as scholars pointed out, far from being static, may be dynamic, or rebuilt or changed in dynamic communicative context; identities have both social and communicative characters, which influence communication with discourse construction; the choice of an identity depends on not only the communicator himself, but also the communicative object; the choice of an identity is often purposeful or even rhetorical ${ }^{[5]}$. In addition to perform file cases against criminal acts, prosecutors are also required to supervise whether the whole trial is conducted strictly in accordance with the relevant regulations and procedures of law. We can check the following dialogue as a further proof:

(2) Prosecutor 1: Did you drive your car straightly?

Defendant: I turned the steering wheel to the left slightly.

Prosecutor 1: You didn't drive your car straightly, so you have an obligation to ensure the safety of the people around you.

(3) Prosecutor 1: Yang Hui, next, the prosecutor will question you and you shall answer truthfully in accordance with relevant laws in our country. If you intend to conceal or fabricate relevant evidences, you shall be liable for it, and you may be subject to criminal punishment possibly if it caused serious results. Are you clear?

Defendant 2: Yes.

The above dialogue reveals that the prosecutor might refer to the suitable articles in his dialogue as suggestions to the judge, or he might accuse the defense lawyer for not having carried out defense rights appropriately, or he would implicitly accuse the defendant and witness for not answering truthfully which would possibly undertake negative legal consequence. This identity construction discourse is typical in institutional discourses, which can guide the whole trial to follow strictly statutory requirements. 


\section{Pragmatic identity variation in Trial Discourse from A Dynamic Perspective}

1) The identity of abusing public power implied in threatening expression discourse

In the trial context, prosecutors might force the defendant to confess the crimes as they have presupposed the defendants as criminals in their mindset. As a consequence, the language they used might contain mistakes of manipulation of discourse and abuse of legal rights. In such cases, the identities as national prosecutors might be variated. Motivated by the desire to excel in the prosecution-defense relationship, prosecutors might use inappropriate diction in the trial as the adversarial party.

The following dialogue between the prosecutor and the defendant could be cited as another evidence for the above analysis:

(4) Prosecutor 2: Defendant, you are required to confess truthfully without seeking for any excuse.

(5) Prosecutor 2: Defendant, you should answer truthfully or the court will punish you severely and even sentence you to life imprisonment.

(6) Prosecutor 1: In accordance with the 67th article of the Criminal Law, if a defendant pleads guilty in court, he or she may be deemed to have surrendered himself or herself. Even if he or she cannot be deemed to have surrendered himself or herself, he or she can be deemed as confession. A person who confesses or surrenders oneself can be treated leniently. Defendant, your attitude might cause a negative result.

Defender 2: Chief judge, the prosecutor was cheating the defendant. The defendant didn't surrender himself to the police voluntarily at the very beginning, so no matter how he will confess in the trial, he will not be deemed to surrender himself voluntarily.

Chief judge: Prosecutor,please raise question centering on the fact in dispute. The court will judge whether the defendant surrender himself voluntarily.

It is obviously seen from the above example that what the defendant had answered didn't conform to what the prosecutor had expected the defendant to.The prosecutor quoted relevant articles and threatened the defendant directly with his identity advantage as a legal professional, who has transcended his legal roles both as a prosecutor and law supervisor with improper act and expression. It was particularly dangerous that, in trials, prosecutors sometimes use coercive expressions to turn the equal prosecutiondefense relationship into unbalanced one by usurpation of public power, which will lead the defendant subordinated to the rule of "power discourse, and ultimately mislead the judgment to lose the essence of justice and fairness .

As is regulated by law, the exercise of public power by prosecutors is supposed to protect the lawful rights and interests of relevant parties. However, if they exercise the power improperly or they depend too much on their identities as legal prosecutors and supervisors of public power, an unequal coercion of discourse power might be formed over the other parties in trials, especially the defendants and their lawyers. Moreover, such ways of expression in trials will also become "bureaucratic discourses". On the surface, "bureaucratic discourse" is a kind of discipline discourse in modern society, which is a representative of various social disciplinary mechanisms (such as governmental agencies and social institutions). Essentially, it is a concentrated reflection of "bureaucrat power" at discourse level, which is an abuse of the power of various social disciplinary mechanisms. The prevalence of "bureaucratic discourses" is one of the main causes for unequal discourse power ${ }^{[10]}$.

2) The identity of legal propagandist implied in educational discourse

The educational function of trials should be unconsciously implanted in all trial interactions according to legal procedures. In real cases, the expressions used in the prosecutor discourse might explicitly conveys educational intention and transformed a serious trial act into an education lesson, in which the prosecutors might be off track with the legal identity. Two more examples here will be examined to prove the point just mentioned.

(7) Prosecutor: ... One who committed many injustices is doomed to failure. At the moment that this gang of robbers fall into the net of justice one by one and finally are taken to the bar to be sanctioned by people, the mass all feel cheerful.

(8) Prosecutor: Any driver should have the awareness of public safety. The defender said that one He Xiaoping had been put into jail, but there were still thousands of persons like He Xiaoping hiding in Lamborghini, Maserati and Aston Matin, Such young persons who are possible to cause similar consequences are still escaped from the responsibilities of school education and social education, so I would like to remind the defender of not misinterpreting the meaning in my words.

As mentioned before, the prosecutor has been deviated from his neutral identity as legal supervisor while using many words with strong emotion, such as "...finally are taken to the bar", "to be sanctioned by people" and "cheerful". Moreover, in the discourse, the prosecutor emphasized and exaggerated the publicity and educational role of judgment excessively, and thus partly turn himself into a legal propagandist and educator in the trial, which lost the neutrality and impartiality that the legal process should have had. The prosecutor are supposed to calmly manipulate his own anger in the crime and strive to justly reveal the truth of the case, make rightful accusation and provide sufficient proofs for the crime in the issue. It is obviously improper to make thoughtless statements, excessive exaggeration or impetuous act for a prosecutor to construct his legal identity. "The success of a prosecutor lies in accurate evidences,proofs and application of the law." [11]

\section{CONCLUSION}

Based on the theories in pragmatic identities, The article, probes emphatically into identity construction of prosecutors in the discourse of criminal trials within the context of the legal institutional identity. It can be concluded from the 
corpus analysis that, in addition to performing the duties of legal supervision and prosecution as a "government lawyer", prosecutors also might have inappropriate behaviors in the interactive dialogues between all other litigation subjects in the specific discourse context of criminal trials and themselves, leading to improper enlargement of their duties in the trails. Before the court has yet to issue a verdict, the prosecutors might use wrongful statement directly to "convict" the defendant. Or, even worse, prosecutors also might change the serious trail into a legal lesson directly, or carry out the education duty of law popularization randomly with too many emotional words, which finally impairs the neutrality and impartiality that they should have as legal professionals.

The priority in the duties of a prosecutor is the supervision duty in the criminal cases. When they perform the prosecution duty, they are supposed to be stipulated and restricted by their identities of legal supervisors with loyal adherence to neutrality, earnest fulfillment of the legal obligations and persistent protection of objectivity and fairness in prosecuting crimes. The duty of legal supervision should be higher than the prosecution duty, so as to realize the equality between the prosecutors and the defendant. Therefore, the correct analysis of various identity constructions of prosecutors in trial discourse context, is conducive to correctly examine the relationship between prosecutors and other litigation subjects from the viewpoint of meta-thinking, eliminate the fragmentation of thinking among all parities, and reach a rational consensus and comprehensive understanding. Hereby it is more effective to guarantee the correct affirmation of facts and application of evidences, stick to the legal spirit of "Trial Centralism", realize the equality of legal status between the prosecutors and defendants, and finally form the basic line to avoid unjust, false and erroneous cases. Meanwhile, it can also reduce the waste of judicial resources and improve the efficiency of litigation ${ }^{[14]}$.

\section{REFERENCES}

[1] Yuan Z. M. Applied Research Review of Identity Construction[J], Shangdong Foreign Language Teaching, 2013 (2) .

[2] Ran Y. P. Interdisciplinary Multidimensional View for Research of Contemporary Pragmatics[J], Foreign Language Teaching and Research, 2011 (5)

[3] Chen X. R. The Social Psychological Dimension for the Research of Contemporary Pragmatics[J], Foreign Languages in China,2009 (4) :

[4] Chen X. R. Key Issues and Main Paths --- Identity Research from the Viewpoint of Pragmatics[J], Modern Foreign Languages,2014 (5):

[5] Chen X. R. Pragmatic identity: Dynamic Selection and Discourse Construction[J], Foreign Language Research,2013 (4).

[6] Haworth, K. The Dynamics of Power and Resistence in Police Interview Discourse[J], Discourse \& Society, 2006(6).

[7] Bogoch, B. Courtroom discourse and the gendered construction of professional identity[J], Law \&Social Inquiry, 1999,24(2).

[8] Zhang J. W. Essence and Representation of Centralism Judgment[N] , People's Court Daily, 2014-6-20.

[9] Chen X. R. Pragmatic identity: Dynamic Selection and Discourse Construction[J], Foreign Language Research, 2013 (4)

[10] Wang F. F. Mechanism Analysis on Control and Abuse of Power of Discourse --- Take the "Official Discourse" as an Example, a Typical
Example of Control and Abuse of Power of Discourse[J], Foreign Language Research,2015 (5) .

[11] Liao M. Z. Trial Communication Strategies[J], Law Press,2010.

[12] Yang R. Research on the Roles and Power in Court Discourse --Research on the Interaction between the Public Prosecutor and the Defendant[J], Legal System and Society, 2012 (4) . 